\title{
Religion as a protective factor against adolescent smoking habits: evidence from Spain
}

\author{
Jorge de Andres-Sanchez ${ }^{a}$, Angel Belzunegui-Eraso ${ }^{b}$, Sonia Fernández-Aliseda $^{c}$ \\ a PhD, Associate Professor, Chair for Social Inclusion, Social and Business Research Laboratory, Universitat Rovira i \\ Virgili, Tarragona, Spain \\ ${ }^{b}$ PhD, Director, Social and Business Research Laboratory, Chair for Social Inclusion, Universitat Rovira i Virgili, \\ Tarragona, Spain. \\ ${ }^{\mathrm{c}}$ MSc, Doctoral Student, Social and Business Research Laboratory, Chair for Social Inclusion, Universitat Rovira i \\ Virgili, Tarragona, Spain
}

\section{Abstract}

Background: There are a wide number of assessments suggesting that being a member of a religious community inhibits adolescents' risky behaviours and, consequently, can act as a protective factor against the consumption of smoking substances.

Methods: We have analysed a structured questionnaire answered by 1935 adolescents from Tarragona (Spain).

Results: We have found that variables linked to family were the principal explanatory factors of adolescents' smoking habits. Living with two parents was a protective factor against tobacco and cannabis use since its Incidence Rate Ratio (IRR) was clearly below $1(p<0.01)$. So, whereas living with one parent showed an IRR $>1(p<0.05)$, adolescents that live without parents presented an IRR close 2 ( $p<0.05$ for tobacco and $p<0.01$ for cannabis). However, having a religious confession also influence smoking substance use in adolescents (IRR close to 0.85 with $p<0.01$ ).

Conclusion: We found a clear preventive effect in belonging to a religious community. Moreover, this protective effect was less intense, but not statistically significant, for Catholics than for members of other confessions.

Key Words: adolescent; religion; tobacco; marijuana; smoking; substance use

\section{Introduction}

The relationship between religious beliefs and risk taking behaviours has been found significant in young people. . $^{1,3,4}$ Religious communities make up social networks that act as role models, provide social and emotional support, and promote the use of free time engaging in safe activities. ${ }^{4}$ Religious practices influence actions and attitudes of persons, including those of adolescents, thereby facilitating the transmission of usually healthy lifestyles ${ }^{5,6}$, that following WHO foundational document must enable "a state of complete physical, mental, and social well-being and not merely the absence of disease or infirmity." Bartkowski \& $\mathrm{Xu}^{5}$ indicated that, for example, regular attendance at religious services in disadvantaged neighbourhoods generated social 
links that reinforced educational values and achievement-minded orientations. Therefore, these same patterns may act as an inhibitor of risk behaviours such as substance abuse or violence. ${ }^{1,5}$

Religion has proven to be a protective factor against the use of tobacco and drugs by helping teenagers belonging to religious communities to internalize messages that discourage their use as shown by empirical research. ${ }^{7,8,9,10,11}$

However, theoretical gaps and contradictory findings about whether belonging to a religious community has a deterrent effect on substance use has also been highlighted. ${ }^{5}$ Although not mainstream, significant research exists that has reported a weak or null influence of religion on drug use. This research has covered cocaine, ${ }^{12}$ tobacco, and illegal drug use. ${ }^{13,14}$ On the other hand, the capability of religion to inhibit can depend on gender ${ }^{10,15}$ or ethnic differences. ${ }^{16}$ The literature has also reported that not all religions have the same protective capability. While there are reports indicating that Christians consume more tobacco than Muslims,${ }^{17}$ other authors have found differences in protective capacity between religions or these effects to be very limited. ${ }^{11,19}$ There are even reports that have shown that some kinds of spirituality were not inhibitors but facilitators of marijuana consumption. . $^{19,20,21}$

The aim of this research is to test the impact of being a member of a religious community on the use of tobacco and cannabis by adolescents. We used a sample of 1935 teenagers of Tarragona (Spain). Our research answered the following two questions: Is religion protective against smoking habits? If so, do different religions in the sample have equal protective power?

\section{Materials and Methods}

This study used a Planet Youth survey. Data come from a structured questionnaire answered by secondary school students of Tarragona that were born in 2001 (12.3\%), 2002 (42.7\%), or $2003(45 \%)$. Gender distribution was $46.74 \%$ boys and $53.26 \%$ girls. The number of interviews was 1,935 , and the sample error was $1.8 \%$ for a confidence level of $95 \%$ and $\mathrm{p}=\mathrm{q}=0.50$. The data were collected between February and March 2019. The questions used in this paper are in Table 1 and the frequencies of responses in every item in Table 2 created using SPSS 20 statistical package.

Table 1. Items of the survey used in this paper

\begin{tabular}{l|l}
\hline Output questions & Answers \\
\hline How much have you smoked cigarettes/cannabis, on & $1=$ Never \\
average, during the last 30 days? & $2=$ "1-2 times" \\
$3=$ "3-5 times" & $4=$ "6-9 times" \\
$5=" 10-19$ times" & $6=$ "20-39 times" \\
$7=$ "c40 times or more" & \\
\hline Input questions & Answers \\
\hline Gender & $0=$ Boy, \\
& $1=$ Girl \\
& $2=$ Other/prefer no answering \\
\hline Are both your parents born abroad? & $0=$ No \\
& $1=$ Yes \\
\hline
\end{tabular}

December 2021. Christian Journal for Global Health 8(2) 


\begin{tabular}{|c|c|}
\hline $\begin{array}{l}\text { Cultural status } \\
\text { Q1= What is your mother studies level? } \\
\text { Q2= What is your father studies level? }\end{array}$ & $\begin{array}{l}0=\text { Basic } \\
1=\text { Secondary } \\
2=\text { Graduate or beyond }\end{array}$ \\
\hline $\begin{array}{l}\text { Family configuration: I live with (please, choose the answer } \\
\text { that suit you best) }\end{array}$ & $\begin{array}{l}1=\text { Mother and father equally } \\
2=\text { Mother but not father } \\
3=\text { Father but not mother } \\
4=\text { Mother and her partner } \\
5=\text { Father and his partner } \\
6=\text { Grandparents and mother/father } \\
7=\text { Only grandparents } \\
8=\text { I live with my friends } \\
9=\text { I live my own } \\
10=\text { I live in different arrangements }\end{array}$ \\
\hline $\begin{array}{l}\text { Family support: } \\
\text { Q1=How easy or hard would it be for you to receive the } \\
\text { following from your parents/legal guardians? - Caring and } \\
\text { warmth } \\
\text { Q2=How easy or hard would it be for you to receive the } \\
\text { following from your parents/legal guardians? - Discussions } \\
\text { about personal affairs } \\
\text { Q3=How easy or hard would it be for you to receive the } \\
\text { following from your parents/legal guardians? - Advice about } \\
\text { your studies } \\
\text { Q4=How easy or hard would it be for you to receive the } \\
\text { following from your parents/legal guardians? - Advice about } \\
\text { other issues (projects) of yours } \\
\text { Q5=How easy or hard would it be for you to receive the } \\
\text { following from your parents/legal guardians? - Assistance } \\
\text { with other things }\end{array}$ & $\begin{array}{l}1=\text { Very difficult } \\
2=\text { Rather difficult } \\
3=\text { Rather easy } \\
4=\text { Very easy }\end{array}$ \\
\hline What religious community do you belong to? & $\begin{array}{l}1=\text { Catholic } \\
2=\text { Lutheran } \\
3=\text { Muslim } \\
4=\text { Orthodox } \\
5=\text { Baptist } \\
6=\text { Other } \\
7=\text { I do not belong to any religious community }\end{array}$ \\
\hline
\end{tabular}

Table 2. Frequencies of the responses to the items

\begin{tabular}{lcc}
\hline Answer & $\begin{array}{c}\text { OUTPUT VARIABLES } \\
\text { Tobacco use }\end{array}$ & Cannabis use \\
\hline $1=$ Never & $73.8 \%$ & $65.0 \%$ \\
$2=$ "1-2 times" & $5.4 \%$ & $7.4 \%$ \\
$3=$ "3-5 times" & $3.0 \%$ & $4.1 \%$ \\
$4=$ "6-9 times" & $5.8 \%$ & $2.8 \%$ \\
$5=$ "10-19 times" & $2.5 \%$ & $3.0 \%$ \\
$6=$ "20-39 times" & $1.2 \%$ & $2.1 \%$ \\
$7=$ "40 times or more" & $1.0 \%$ & $5.7 \%$ \\
Failed/refused to answer & $7.4 \%$ & $10.0 \%$ \\
\hline
\end{tabular}

\section{INPUT VARIABLES}

Variable

Gender

Parents

\section{Responses (frequency)}

Boys (46.7\%); Girls (52.3\%)

Both parents were born abroad (18\%); At least one parent was born in Spain (70.6\%); Failed/refused to answer (3.5\%) 


\author{
Cultural status \\ Q1 (Mother) \\ Q2 (Father) \\ Family arrangement \\ Family Support \\ Q1 (Caring and warm) \\ Q2 (Discussions about \\ personal affairs) \\ Q3 (Advice about the \\ studies) \\ Q4 (Advice about other \\ issues of yours) \\ Q5 (Assistance with other \\ things)
}

Religious community
Basic (15\%); Secondary (34.3\%); Graduate or beyond (26.7\%); Failed/refused to answer $(24 \%)$

Basic (15.2\%); Secondary (33\%); Graduate or beyond (23\%); Failed/refused to answer $(28.8 \%)$

Lives with both parents (75.1\%); Lives with one parent (20.2\%); Other status (3\%); Failed/refused to answer $(1.7 \%)$
Very difficult (2.4\%); rather difficult $(8.4 \%)$; rather easy $(26 \%)$; very easy (60.4\%); Failed/refused to answer $(2.8 \%)$

Very difficult $(12.6 \%)$; rather difficult $(26.7 \%)$; rather easy $(31.7 \%)$; very easy (26.3\%); Failed/refused to answer $(2.7 \%)$

Very difficult $(6.6 \%)$; rather difficult $(12.1 \%)$; rather easy $(30.1 \%)$; very easy (48.2\%); Failed/refused to answer (3\%)

Very difficult $(6.2 \%)$; rather difficult $(16.2 \%)$; rather easy $(31.3 \%)$; very easy

(43.3\%); Failed/refused to answer (3\%)

Very difficult $(5.6 \%)$; rather difficult $(11.8 \%)$; rather easy $(31.4 \%)$; very easy

(48.2\%); Failed/refused to answer (3\%)

Failed/refused to answer (1.4\%)

Those questions concerning substance consumption are by Bartkowski \& $\mathrm{Xu}^{5}$, whereas to measure family support we used questions proposed in Hwang \& Awkers. $^{22}$ Regarding ethical approval, (1) all participants and their legal guardians were informed about the study and procedure; (2) anonymity of the data collected was ensured at all times; (3) voluntary completion of the questionnaire was taken as consent for the data to be used in research, and the participants' informed consent was implied by their completing the survey. Teachers supervised the surveyed adolescents (if they and their legal guardians agreed) to be sure the questions were understood. Researchers were unable to link specific respondents with a given observation. The parents of the participants were informed about the study, and in those educational centres where it was deemed necessary, parents gave written consent. The study was authorized by the ethics committee of the researchers' institution, as it met the Official College of Psychologists of Spain and Belmont report.

\section{Explained variables}

TOBACCO/CANNANBIS, are the ordinal variables in Table 1. As control variables we consider:

- $\mathrm{SEX}=$ Variable that can take 0 (girl) or 1 (boy)

- COUNTRY = Variable is 0 (if two parents were born abroad) or 1 (otherwise)

- CULT_ST= It is built from normalizing the sum of responses Q1 and Q2 . CULT_ST= $((\mathrm{Q} 1+\mathrm{Q} 2)-2) / 4$

- ONLY_ONE_P=Its value is 1 if adolescent lives only with one of the parents and 0 otherwise.

- NO_PAR= Its value is 1 if teenager does not live with any parent and 0 otherwise. 
- FAM_SUP= Punctuation for the first factor in factorial analysis of questions about family support.

\section{Variables for religiosity}

- RELIGIOUS= Its value is 1 if the response is between 1 and 6 and 0 otherwise.

- CATHOLIC/LUTHERAN/MUSLIM/ ORTHODOX= Its value is 1 if the adolescent confesses belonging to that religious community and 0 otherwise.

We ran two truncated Negative Binomial regressions over TOBACCO and CANNANBIS by using EViews 11 software. Both regressions included all control variables. In the first model, we also included RELIGION as explanatory variable. In the second model, we removed RELIGION and included dichotomous variables linked to concrete confessions. This last regression analysis investigated the particular influence of each religion on tobacco and cannabis use and also allowed checking if different religions in the sample present the same protection capability. To accomplish this, we ran a Wald test whose null hypothesis was that there is no difference between the IRR of religions and smoking consumption.

\section{Results}

In our sample there were 665 Catholics (34.8\%), 44 Lutherans (2.3\%), 115 Muslims (6\%), 30 Orthodox (1.6\%). 995 adolescents (52.1\%) professed no particular confession. The FAM_SUP questionnaire had internal consistency since its Cronbach's alpha is 0.844 . Factor analysis revealed that the first factor is enough to represent this variable.

Table 3 shows the results by the adjustment of regression models.

Table 3. Coefficients of Negative Binomial regressions

\begin{tabular}{lcccc}
\hline Input|Output & TOBACCO & CANNABIS & TOBACCO (2) & CANNABIS (2) \\
\hline Constant & $2.255^{* * *}$ & $2.319^{* * *}$ & $2.239^{* * *}$ & $2.298^{* * *}$ \\
SEX & $1.132^{* *}$ & $0.752^{* * *}$ & $1.136^{* *}$ & $0.752^{* * *}$ \\
COUNTRY & 0.968 & $0.849^{* *}$ & 1.004 & $0.854^{* *}$ \\
CULT_ST & 1.021 & 0.967 & 1.014 & 0.968 \\
ONLY_ONE_P & $1.172^{* *}$ & $1.226^{* * *}$ & $1.175^{* *}$ & $1.230^{* * *}$ \\
NO_PAR & $1.998^{* * *}$ & $1.623^{* * *}$ & $1.968^{* * *}$ & $1.609^{* * *}$ \\
FAM_SUP & $0.923^{* * *}$ & $0.908^{* * *}$ & $0.923^{* * *}$ & $0.909^{* * *}$ \\
RELIGION & $0.844^{* * *}$ & $0.838^{* * *}$ & --- & -- \\
CATHOLIC & --- & --- & $0.863^{* * *}$ & $0.848^{* * *}$ \\
LUTHERAN & --- & --- & 0.634 & 0.828 \\
MUSLIM & --- & $---0.630^{* *}$ & 0.745 \\
ORTHODOX & --- & 0.740 & 0.810 \\
R & 0.051 & 0.075 & 0.055 & 0.008 \\
Adjusted R & 0.045 & 0.068 & 0.046 & 0.066 \\
\hline
\end{tabular}

Notes: (1) As “*”, “**” and “***” we denote that the coefficient is statistically significant at 0.1, 0.05 and 0.01 level respectively. (2) Chi-squared statistic for the null hypothesis "coefficients of CATHOLIC, LUTHERAN, MUSLIM and ORTODOX are not different" in the regression TOBACCO (2) is $4.164(p=0.244)$. In the case of CANNABIS (2), Chi squared= $0.566(p=0.906)$. 
Variables related to adolescent family environment were consistently significant. Not living with both parents increased the risk of smoking any substance. So, for ONLY_ONE_P, the incidence rate ratio (IRR) was 1.17 and 1.23 $(p<0.01)$ and for NO_PAR, that IRR increased to $1.6-2$ ( $p<0.01$ for cannabis and $\mathrm{p}<0.05$ for tobacco). Perceiving family support also acted as a protective factor $(I R R=0.9-0.92, p<0.01)$.

Girls were more exposed than boys to tobacco $(\mathrm{IRR}=1.17-1.23$ with $\mathrm{p}<0.05)$ and boys than girls to cannabis $(\operatorname{IRR}=0.732, \mathrm{p}<0.01)$. Having both parents of immigrant status may have been a protective factor against cannabis consumption ( $\mathrm{IRR}=0.854$, $\mathrm{p}<0.05$ ), but this variable did not influence tobacco use. Parents' cultural status did not contribute towards an explanation for the use of substances.

We found that belonging to any religious community was protective. For the variable RELIGION, we fit $\mathrm{IRR}=0.838-0.844 \quad(\mathrm{p}<0.01)$. Likewise, all IRRs of CATHOLIC/ LUTHERAN/ MUSLIM/ORTHODOX are always under 1.

By analysing the value of IRRs of assessed religions, we concluded that they were greater for Catholicism than for other confessions. So, Catholicism might have a poorer inhibition effect toward assessed smoking substances. On the other hand, IRR of Catholics is unique with a statistical significance consistently below 1 for both tobacco and cannabis smoking $(\mathrm{p}<0.01)$. Wald test on the equality of coefficients linked to concrete religions cannot reject either for tobacco or for cannabis and that the protective capability of religions in our sample is the same.

\section{Discussion}

Results suggest that religion serves as a protective factor for teenagers against tobacco and cannabis consumption and that the practice of any of the four tested religions has the power to inhibit smoking. Therefore, our findings are consistent with the mainstream of the literature on the topic. ${ }^{1-12}$ Despite the finding that only the Catholic religion was associated with a statistically significant IRR under 1, other religions (Muslim, Lutheran, and Orthodox) present an IRR lower than that of the Catholic religion. It could be suggestive of a difference between religions in the inhibitory power against smoking as it is found in Hussein et al. ${ }^{17}$ However, the failure of Wald tests to show the significance of that difference might be due to low number of non-Catholics in the survey.

We have also checked that boys are more exposed to cannabis use whereas girls are more likely to use tobacco. This fact is in accordance with studies showing that gender is a relevant variable to explain substance use. ${ }^{5,11,22} \mathrm{We}$ found that the configuration and support of the family are decisive factors to inhibit smoking habits., ${ }^{5,11,22}$ On the contrary, we have not found relevant cultural status of parents to prevent smoking tobacco and cannabis, which contradicts some findings. ${ }^{5,11,14}$ Likewise, as in other literature, ${ }^{14,16}$ we have detected relevant cultural and ethnic differences to explain cannabis consumption, but this finding does not follow for tobacco.

The findings in this paper reinforce studies which report that belonging to a religious community provides a social capital that prevents substance use. Among public health policymakers, it is generally agreed that engaging in activities in secular environments, such as academic clubs and sports teams, have an inhibitory capacity. However, this does not always follow when it comes to activities in religion-based networks. Health authorities should be made aware that conducting activities in religious settings can also be an invaluable way to limit substance use among young people.

This study has several limitations. As we mentioned earlier, the number of responses from non-Catholic religious teenagers is low, and hypothesis tests on specific religions may therefore lack statistical power. Moreover, since the survey is not longitudinal, the robustness of its results may be limited over time. Other experiments or further information that could strengthen this paper include 
gathering a larger cohort and conducting the survey in geographical areas with different religious distributions or socioeconomic characteristics. We should point out, however, that since Tarragona's economy is based on services and the chemical industry, our sample may be representative of similar Western European cities but not, for example, of Spanish rural areas.

In this paper, we have analysed how adolescents' feelings of belonging to a religious community influence their smoking of substances. However, this analysis involves a rough representation of religiosity that does not take into account its multiple nuances. Further research into which dimensions of religion are really protective and which ones provide better and more sustainable results than social or community services should be conducted. We also believe it would be useful to investigate the role of gender and analyse how it relates to the influence of religion in this area.

\section{References}

1. King PE, Roeser RW. (2009). Religion and spirituality in adolescent development. In: Lerner RM, Steinberg L, editors. Handbook of adolescent psychology: individual bases of adolescent development. John Wiley \& Sons Inc.; p. 435-78. https://doi.org/10.1002/9780470479193.adlpsy001014 2 .

2. Arli D, Cherrier H, Lasmono H. The Gods can help: exploring the effect of religiosity on youth risk-taking behaviour. In: Indonesia. Int J Nonprof Volunt Sec market. 2016;21(4):253-68. https://doi.org/10.1002/nvsm.1558

3. Buchtova M, Malinakova K, Kosarkova A, Husek V, van Dijk JP, Tavel P. Religious attendance in a secular country protects adolescents from health-risk behavior only in combination with participation in church activities. Int J Env Res Pub He. 2020;17(24):1-13. https://doi.org/10.3390/ijerph17249372

4. Moulin-Stożek D., de Irala J, Beltramo C, Osorio A. Relationships between religion, risk behaviors and prosociality among secondary school students in Peru and El Salvador. J Moral Educ. 2018;47(4):466-80. https://doi.org/10.1080/03057240.2018.1438250

5. Bartkowski JP, Xu X. Religiosity and teen drug use reconsidered: a social capital perspective. Am J Prev Med. 2007;32(6):S182-S94.

6. WongYJ, Rew L, Slaikeu KD. A systematic review of recent research on adolescent religiosity/spirituality and mental health. Issues Ment Health $\mathrm{N}$.

2006;27:161-83.

https://doi.org/10.1080/01612840500436941

7. Ford JA, Hill TD. Religiosity and adolescent substance use: evidence from the National Survey on Drug Use and Health. Substance Use \& Misuse. 2012;47(7):787-98. https://doi.org/10.3109/10826084.2012.667489

8. Acheampong AB, Lasopa S, Striley CW, Cottler LB. (2016). Gender differences in the association between religion/spirituality and simultaneous polysubstance use (SPU). J Relig Health. 2016;55:1574-84. http://doi.org/10.1007/s10943-015-0168-5

9. Ameri Z, Mirzakhani F, Nabipour AR, Khanjani N, Sullman MJM. The relationship between religion and risky behaviors among Iranian university students. J Relig Health. 2017;56:2010-22. http://doi.org/10.1007/s10943-016-0337-1

10. Parenteau S. Religious coping and substance use: the moderating role of sex. J Relig Health. 2017;56:3807. http://doi.org/10.1007/s10943-015-0166-7

11. Francis JM, Myers B, Nkosi S, Petersen Williams P, Carney T, Lombard C, et al. The prevalence of religiosity and association between religiosity and alcohol use, other drug use, and risky sexual behaviours among grade 8-10 learners in Western Cape, South Africa. PloS one. 2019;14(2):e0211322. https://doi.org/10.1371/journal.pone.0211322

12. Jeynes WH. Adolescent religious commitment and their consumption of marijuana, cocaine, and alcohol. J Health Soc Polic. 2006;21:1-20. https://doi.org/10.1300/J045v21n04 01

13. Lorch BR, Hughes RH. Religion and youth substance use. J Rel Health. 1985;24: 197-208. https://doi.org/10.1007/BF01597313

14.Parsai M, Marsiglia FF, Kulis S. Parental monitoring, religious involvement and drug use among Latino and non-Latino youth in the Southwestern United States. Brit J Soc Work. 2010;40(1):100-14. https://doi.org/10.1093/bjsw/bcn100 
15. Piko BF, Fitzpatrick KM. Substance use, religiosity, and other protective factors among Hungarian adolescents. Addict Behav. 2004;29(6):1095-107. https://doi.org/10.1016/j.addbeh.2004.03.022

16. Rote S, Starks B. Racial/ethnic differences in religiosity and drug use. J Drug Issues. 2010;40:72954.

17. Hussain M, Walker C, Moon G. Smoking and religion: untangling associations using English Survey Data. J Rel Health. 2019;58(6):2263-76. https://doi.org/10.1007/s10943-017-0434-9

18. Gmel G, Mohler-Kuo M, Dermota P, Gaume J, Bertholet N, Daeppen JB, et al. Religion is good, belief is better: religion, religiosity, and substance use among young Swiss men. Subst Use Misuse. 2013;48:1085-98. https://doi.org/10.3109/10826084.2013.799017

19. Lorencova R. Religiosity and spirituality of alcohol and marijuana users. J Psychoactive Drugs.
2011;43(3):180-7.

https://doi.org/10.1080/02791072.2011.605650

20. Adamczyk A, Palmer I. Religion and initiation into marijuana use: the deterring role of religious friends. $\mathrm{J}$ Drug Issues. 2008;38:717-42. https://doi.org/10.1177/002204260803800304

21. Yeterian JD, Bursik K, Kelly JF. "God put weed here for us to smoke": a mixed-methods study of religion and spirituality among adolescents with cannabis use disorders. Subst Abus. 2018;39(4):484-92. https://doi.org/10.1080/08897077.2018.1449168

22. Hwang S, Akers RL. Substance use by Korean adolescents: a cross-cultural test of social learning, social bonding, and self-control theories. Social learning theory and the explanation of crime. 2003;11:39-64. https://doi.org/10.4324/9781315129594-2

Peer Reviewed: Submitted 31 Aug 2021, accepted 17 Nov 2021, published 27 Dec 2021

Competing Interests: None declared.

Correspondence: Jorge de Andres-Sanchez, Tarragona, Spain. jorge.deandres@urv.cat

Cite this article as: Andres-Sanchez J, Belzunegui-Eraso A, Fernández-Aliseda S. Religion as a protective factor against adolescent smoking habits: evidence from Spain. Christ J Global Health. Dec 2021;8(2):16-23. https://doi.org/10.15566/cjgh.v8i2.579

(C) Authors. This is an open-access article distributed under the terms of the Creative Commons Attribution License, which permits unrestricted use, distribution, and reproduction in any medium, provided the original author and source are properly cited. To view a copy of the license, visit http://creativecommons.org/licenses/by/4.0/ 